\title{
VKLJUČEVANJE KMETOV V OSKRBNE VERIGE: PRIMER DOPOLNILNIH DEJAVNOSTI NA SLOVENSKIH KMETIJAH
}

\author{
dr. Irma Potočnik Slavič \\ Oddelek za geografijo Filozofska fakulteta Univerze v Ljubljani \\ Aškerčeva 2, SI-I000 Ljubljana \\ e-mail: irma.potocnik@ff.uni-lj.si
}

Izvirni znanstveni članek

COBISS 1.01

\section{Izvleček}

Vse večjemu delu slovenskih kmetij predstavlja kmetovanje čedalje bolj možnost za pridobivanje dopolnilnega dohodka in za uveljavitev drugotnih interesov (rodbinska tradicija, možnost za preživljanje prostega časa ipd.). Registracija dopolnilnih dejavnosti na kmetiji spodbuja postopen razvoj podjetništva na podeželju, ker temeljijo predvsem na rabi endogenih potencialov kmetije in podeželja ter prispevajo k zagotavljanju lokalne oskrbe s hrano in storitvami za potrebe lokalne skupnosti.

Ključne besede: dopolnilna dejavnost na kmetiji, podeželje, kmetijstvo, lokalna oskrba s hrano, Slovenija

\section{FARMERS' INTEGRATION INTO PROVISION NETWORKS: THE CASE OF SUPPLEMENTARY ACTIVITIES ON FARMS IN SLOVENIA}

\begin{abstract}
In Slovenia agriculture is evidently becoming less economically important activity in rural areas and even for farm households. The basic function of food production has been replaced by various activities mostly in order to generate diversification of farm income, to preserve family tradition or to perform leisure activities etc. The registration of supplementary activities on farms stimulates progressive entrepreneurship development. These activities are based upon (prudent, sustainable) use of farm's endogenous potentials and contribute to the provision of local food and services network.
\end{abstract}

Key words: supplementary activity on farm, rural areas, agriculture, local food and services provision, Slovenia 


\section{UVOD}

Podjetniške, geografske in sociološke značilnosti kmetij v Sloveniji dokazujejo, da se je ta segment kmetijstva znašel v procesu intenzivnega spreminjanja. Pri razmeroma majhnem delu kmetij je vse bolj izrazita težnja po večanju obratov in čedalje doslednejšem upoštevanju podjetniških načel in prijemov pri gospodarjenju, kar zahteva intenzivni oziroma že kar industrijski način proizvodnje. Večinskemu delu kmetij pa kmetovanje vse bolj pomeni možnost za pridobivanje dopolnilnega dohodka in za uveljavitev drugotnih interesov, kot so ohranjanje rodbinske tradicije, ohranjanje določene eksistenčne varnosti za primer morebitnih kriznih situacij, možnost za preživljanje prostega časa ipd. Ta del kmetij bo tudi v bodoče številčno prevladoval. Kovačič (2001) ugotavlja, da nakazana polarizacija nakazuje na smiselnost diferenciacije agrarnopolitičnih ukrepov, ker naj bi:

- poklicnim kmetijam pomagali pri tehnološkem razvoju in optimizaciji obsega proizvodnje do take stopnje, da bodo postale ob doseganju primerljivega dohodka konkurenčno in razvojno sposobne;

- kmetijam, katerim bo kmetijstvo pomenilo dopolnilni dohodek, zagotavljali tako in toliko pomoči, da jih bo spodbujala k obdelovanju kmetijske zemlje (ohranjanje proizvodnega potenciala), kar pomeni, da mora biti tudi taka proizvodnja glede na vložen obseg dela in kapitala gospodarsko zanimiva; poleg tega pa bo treba za potrebe presežne delovne sile na teh kmetijah zagotoviti dovolj delovnih mest $\mathrm{v}$ dopolnilnih dejavnostih in drugih gospodarskih sektorjih, kar pa ne more bi naloga samo (čeprav tudi) kmetijske politike.

Spodbujanje lokalne oskrbe, na primer s hrano in storitvami, pomeni okrepitev posameznih proizvodnih procesov (proizvodnje, predelave, potrošnje in reciklaže) znotraj predvidenega funkcionalnega območja. V ekonomski teoriji se za tovrstni poenostavljeni prikaz pretoka blaga, kapitala, storitev ipd. uporablja izraz (regionalni) gospodarski krog (Maier 2002). Današnje stanje v Sloveniji, pa tudi v EU, nakazuje, da se imenovani krogi večinoma napajajo z zunanjimi viri: surovine se uvažajo, predelava poteka večinoma izven območja pridelave, distribucijo in trgovino vodijo veliki sistemi, odpadki se predelujejo v manjši meri, ostajajo znotraj območja ali pa jih odvažajo na druge lokacije. Zelo pogosti so primeri, ko neko kmetijsko pridelovalno območje izvaža surovino (na primer žito), vendar kmetje in potrošniki znotraj funkcionalnega območja ne morejo kupiti domače moke (večina mlinov je propadla), kot tudi ne v lokalnem okolju pripravljenega kruha (velike pekarne so v večjih središčih, moka prihaja z globalnih trgov). Pridelovalci so tako izvozniki surovine in kupci pol- in končnih izdelkov, dodana vrednost znotraj funkcionalnega območja je zanemarljiva. $Z$ vidika krepitve lokalne oskrbe, zlasti njenih pozitivnih gospodarskih, socialnih, zdravstvenih in okoljskih učinkov (več delovnih mest v lokalnem okolju, krepitev lokalnega/regionalnega gospodarstva, zmanjšanje transportnih stroškov, manjše obremenjevanje okolja, uživanje lokalne in sezonsko pridelane hrane, ohranjanje lokalnih tradicionalnih jedi ipd.), bi bilo v prihodnosti nujno potrebno vzpostaviti čim močnejše vezi znotraj predvidenega funkcionalnega območja. Potrebno bi bilo jasno, ciljno, tržnim spremembam prilagojeno, dinamično povezovanje med proizvajalci in predelovalci, med predelovalci in lokalnimi/ regionalnimi distributerji, trgovci, večjimi in manjšimi porabniki oziroma udeleženci v vseh fazah proizvodnega procesa (Potočnik Slavič 2008; 2010). 
V praksi je lokalna oskrba zelo zapleten, vertikalno in horizontalno povezan, hierarhiziran sistem (slika 1), v katerem kmet posameznik predstavlja le drobno, a izvorno celico tega soodvisnega sistema (od proizvodnje, preko predelave, prodaje, do potrošnje). V prispevku želimo analizirati, kakšni vzroki, pobude, odločitve ipd. so potrebne, da se tovrstne vezi vzpostavijo - in to z vidika kmeta, neposrednega proizvajalca hrane in ponudnika raznovrstnih storitev.

Slika 1: Vertikalno in horizontalno povezovanje akterjev v živilskopredelovalni verigi oziroma regionalnih gospodarskih krogih

Figure 1: Vertical and horizontal linking of stakeholders involved in food-processing industry and respectively in regional economic cycle

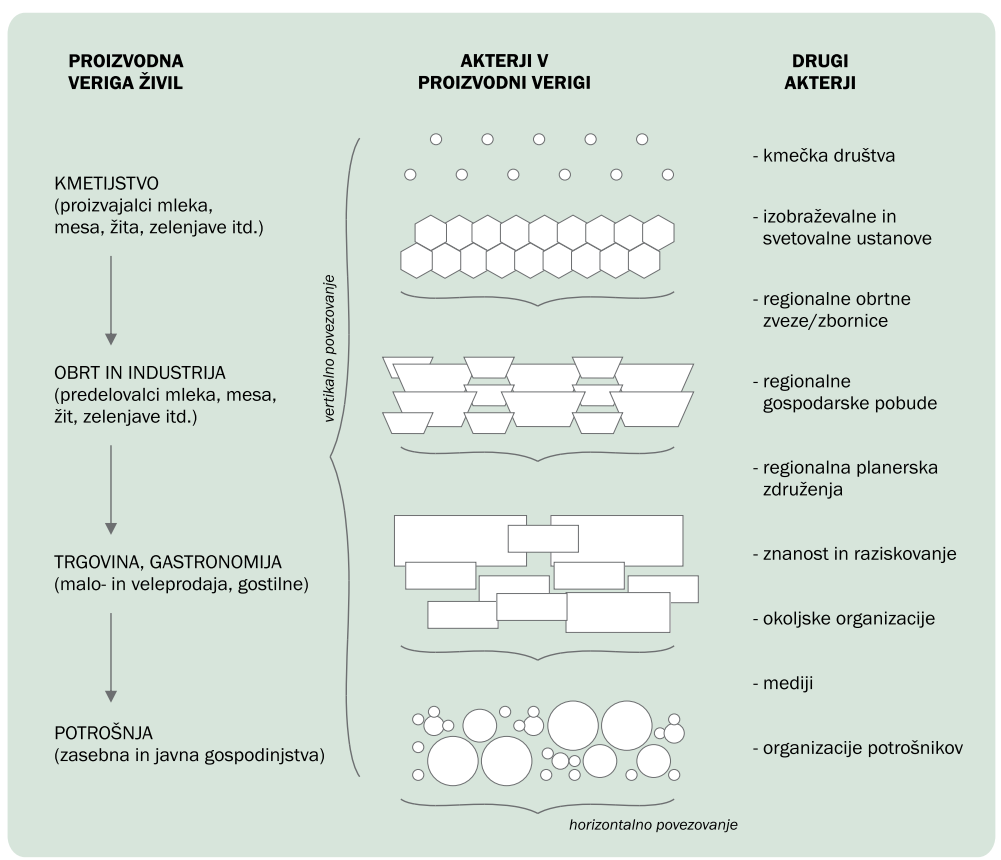

Vir: povzeto in prirejeno po Hofer in Stalder (2000)

Source: adapted after Hofer and Stalder (2000)

Trenutno stanje v Sloveniji izkazuje večinoma povsem nasprotne silnice, kar potrjuje dejstvo, da se je v Sloveniji v zadnjem desetletju stopnja samooskrbe s hrano, podobno pa velja tudi za nekatere storitve (zapiranje majhnih maloprodajnih trgovin na podeželju, zapiranje in životarjenje nekaterih obrti, nevarnost zapiranja podružničnih šol, pomanjkljiva zdravstvena oskrba ipd.) silovito znižala. Problematika je izredno kompleksna: za tovrstno stanje je poleg trgovskih, distribucijskih in širših političnoekonomskih razlogov potrebno izpostaviti tudi dejstvo, da je velika večina kmetij v Sloveniji samooskrbnih. Le-to je posledica več medsebojno povezanih vzrokov: 
- drobna in razdrobljena posest onemogoča velikopotezno tržno kmetovanje;

- omejeni dejavniki za kmetovanje zmanjšujejo tržno konkurenčnost slovenskih kmetij;

- razvojno omejevanje kmetijstva in zemljiške operacije po drugi svetovni vojni so večinoma onemogočile in oslabile podjetniški duh med kmeti;

- nejasne, pogosto spreminjajoče in izjemno zahtevne tržne razmere vnašajo med kmete določen nemir in negotovost, zato je posledična tudi (tradicionalna) večja previdnost glede tovrstnih naložb;

- polkmečka struktura gospodinjstev je generirala zadostno količino pridelkov za potrebe kmečkega gospodinjstva in razširjene družine/sorodnikov;

- premalo odločni posegi kmetijske politike.

\section{METODOLOGIJA}

Zastavljena vprašanja so kompleksne narave, zanje je mogoče vsaj delno pridobiti odgovore iz obstoječih podatkovnih baz. Sliko, ki se skriva za tem, pa je treba pridobiti z odkrivanjem zakonitosti številnih individualnih zgodb, kar nam omogoča obsežno, dolgotrajno in poglobljeno terensko delo. Le-to nam omogoča razbrati, zakaj so kmetije na nekaterih območjih intenzivno vključene ali izključene iz sistema lokalne oskrbe.

Raziskava $^{1}$ se ni osredotočila na kmetije, ki pridobivajo hrano za ožje ali razširjeno gospodinjstvo (t.i. samooskrbne kmetije), ampak na kmetije, ki svoje presežke nudijo trgu in iz samooskrbnih postopoma preraščajo v širše oskrbne (tržne) kmetije, vključene v sisteme oskrbe s hrano in storitvami. Gre za kmetije, ki jim uradno lahko sledimo po registru Ministrstva za kmetijstvo, gozdarstvo in prehrano in se označujejo kot kmetije z registrirano dopolnilno dejavnostjo na kmetiji. Le-to pomeni, da lahko poleg osnovne kmetijske dejavnosti $\mathrm{v}$ omejenem, zakonsko določenem obsegu (Uredba o vrsti, obsegu in pogojih za opravljanje dopolnilnih dejavnosti na kmetiji 2005; Pravilnik o registraciji dopolnilnih dejavnosti na kmetiji 2005) opravljajo druge dejavnosti, iz katerih pridobivajo dohodek.

Število registriranih dopolnilnih dejavnosti na kmetijah po slovenskih občinah občutno raste. Leta 2004 jih je bilo 2215 (Klemenčič in sod. 2008), štiri leta kasneje že 4716, kar je hitrejši porast kot so ga zabeležili številni gradbeni in drugi poslovni subjekti v času gospodarske konjunkture. Vzporedno s tem imamo dokaze, da se je povečalo tudi število kmetij, ki so registrirale dopolnilno dejavnost: 2802 kmetiji v Sloveniji imata prijavljeno eno ali več dopolnilnih dejavnosti na kmetiji (Register... 2008). Dejavnosti, ki jih opredeljuje uredba in vodi register, so na osnovi šifranta razvrščene v 11 vrst dopolnilnih dejavnosti: od predelave, preko turizma na kmetiji, storitev za lokalno skupnost, pridobivanja energije, čebelarstva, trsničarstva itn. Zaradi spremembe šifranta je neposredna primerjava med letoma 2004 in 2008 nekoliko težja: spremenile so se oznake dejavnosti, nekatere dejavnosti novega šifranta so evidentirane pod drugo oznako, nekatere dejavnosti (aranžiranje in izdelava vencev, šopkov) so v šifrant 2008 vključene na novo. V obdobju 2004-2008 se je število registriranih dopolnilnih dejavnosti na kmetiji povečalo za $113 \%$. V absolutnem smislu se je najbolj pove-

\footnotetext{
${ }^{1}$ Raziskava na kmetijah z registrirano dopolnilno dejavnostjo je bila izvedena v zimskem semestru študijskega leta 2009/2010 v okviru vaj iz predmeta Geografija podeželja. Vsem študentkam in študentom, ki so sodelovali pri izvedbi ankete, se iskreno zahvaljujem.
} 
Sliki 2 in 3: Primerjava števila registriranih dopolnilnih dejavnosti na kmetiji v Sloveniji med letoma 2004 in 2008

Figures 2 and 3: The number of registered supplementary activities on farms in Slovenia (comparison 2004-2008)
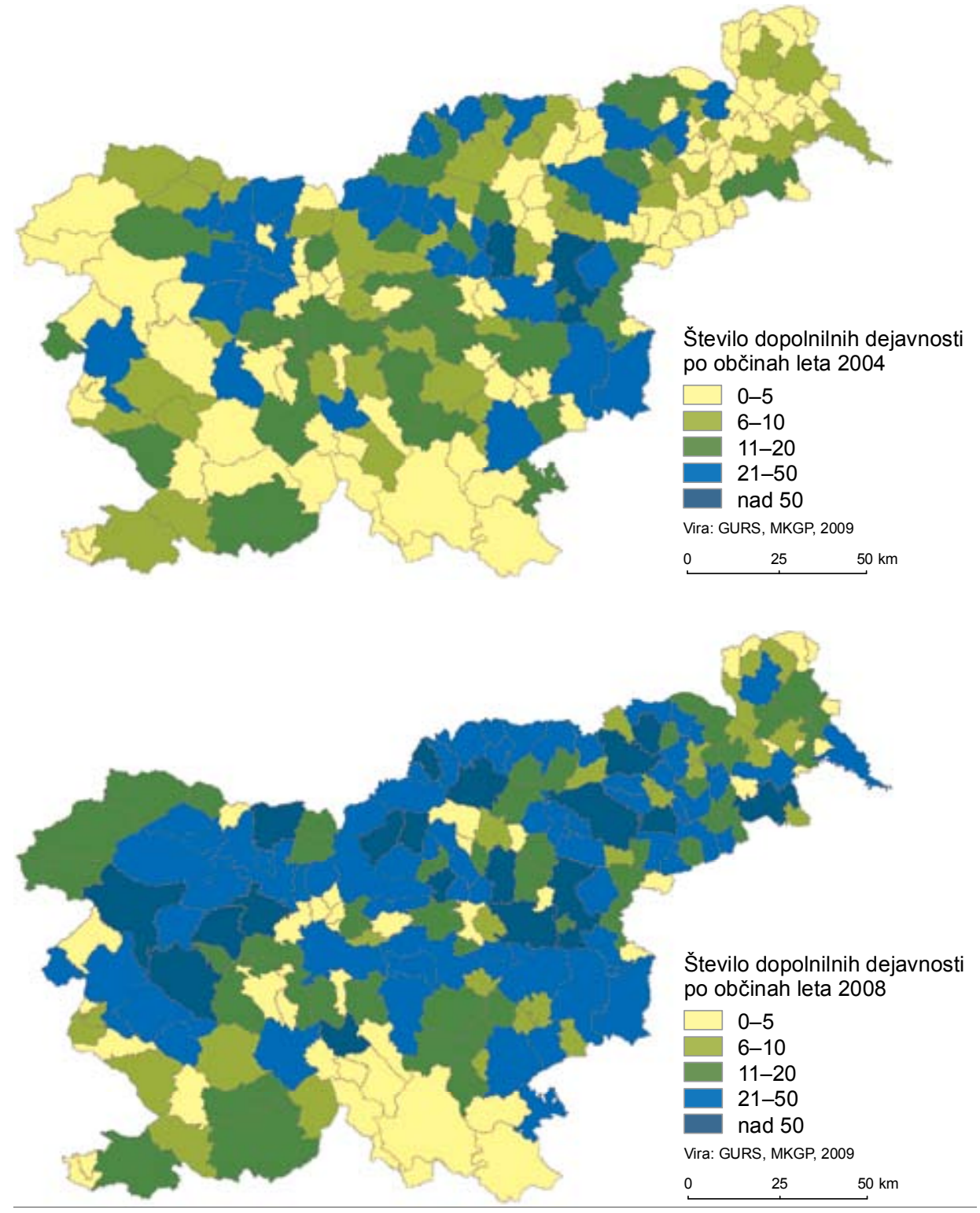
Sliki 4 in 5: Primerjava števila kmetij z registrirano dopolnilno dejavnostjo v Sloveniji med letoma 2004 in 2008

Figures 4 and 5: Number of registered farms with supplementary activities on farm in Slovenia (2004-2008)
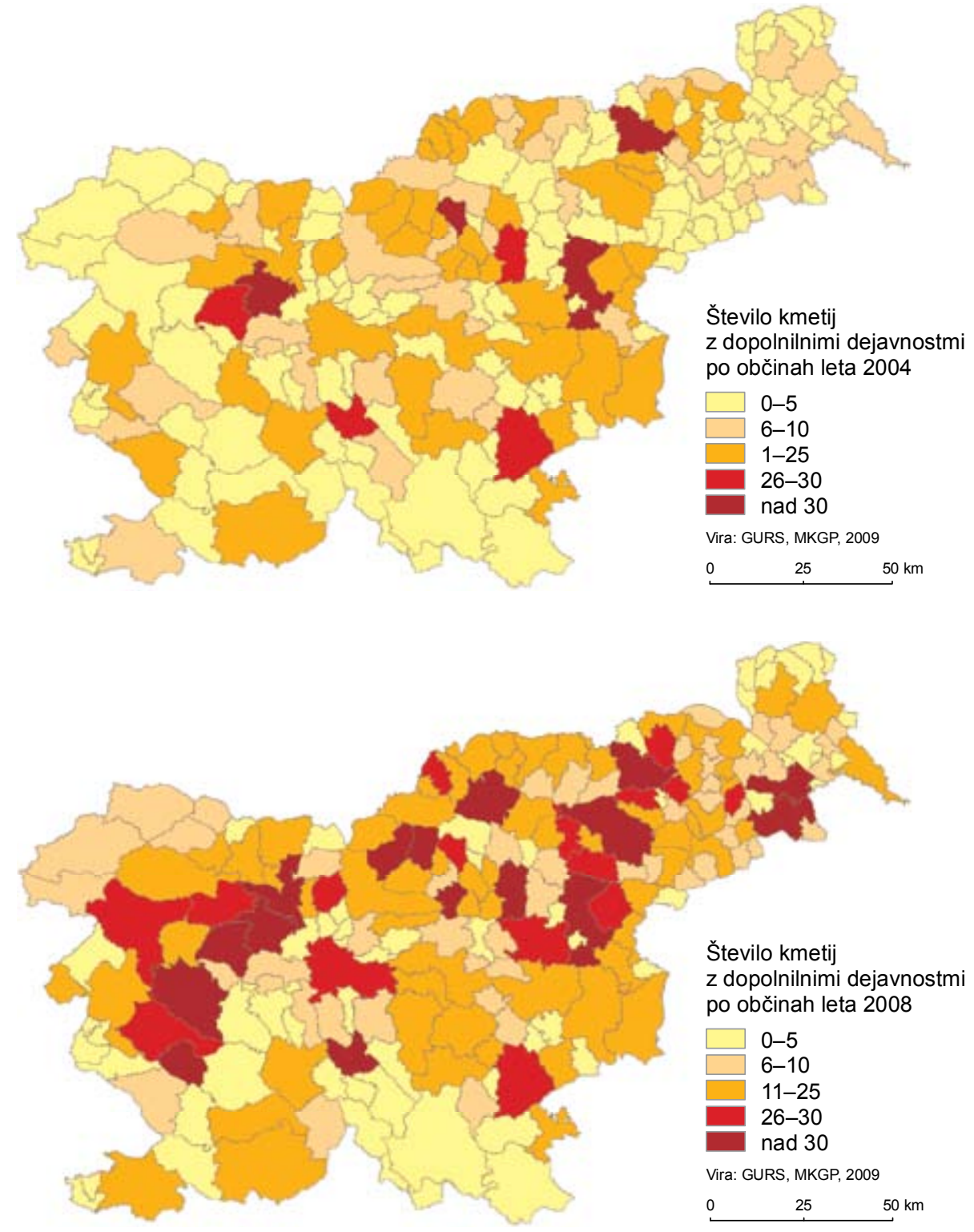
čalo število storitev s kmetijsko in gozdarsko mehanizacijo (za 1103), kar je odraz specifičnosti te vrste dejavnosti, ki je predvsem v opravljanju storitev za potrebe lokalne skupnosti, letnega časa oziroma prilagajanja obstoječim predpisom, ki ob prijavi te dejavnosti s formalnega vidika omogočajo relativno enostavno pridobitev alternativnega vira dohodka. Za $49 \%$ se je povečalo število dejavnosti predelave kmetijskih pridelkov, za $77 \%$ pa število registriranih turističnih dejavnosti na kmetiji. Opazen je tudi porast drugih dejavnosti (oznaka 11) za $263 \%$, kar je med drugim tudi posledica vsebinske širine te kategorije, ki dopušča kmetom večjo inovativnost glede razvoja dopolnilnih dejavnosti in povečanje števila dejavnosti, povezanih s tradicionalnimi znanji (za 246 \%). Pri ostalih vrstah dejavnosti je tudi prišlo do opaznega absolutnega povečanja, kot na primer pri izobraževanju na kmetijah, pridobivanju in prodaji energije iz obnovljivih virov, prodaji izdelkov in pridelkov okoliških kmetij (Potočnik Slavič 2008).

Večja zgostitev dopolnilnih dejavnosti na kmetiji je vidna na kmetijah v občinah Zahodnega predalpskega hribovja, v Zgornji Savinjski dolini, v Podravju, Slovenskih goricah, spodnjem Posavju, na območjih, kjer je zaradi neugodnih naravnogeografskih dejavnikov za kmetovanje že tradicionalno prisotno iskanje več virov dohodkov, ali pa na območjih, kjer se širi mreža kmetij z registrirano dopolnilno dejavnostjo zaradi doživljajske zmožnosti pokrajine (turizem na kmetiji) in specifičnih kmetijskih kultur (vino, sadje) ter predvsem njihove predelave.

S pomočjo uradnih evidenc smo želeli ugotoviti, če prihaja do regionalne specializacije glede na število in vrsto registriranih dopolnilnih dejavnosti. Poskus tovrstne tipizacije je precej subjektiven, saj izhodišča temeljijo na nizkih frekvencah izbranih pojavov, izhaja pa iz sledečih predpostavk (slika 6 in preglednica 1).

S pomočjo podatkov registra (2008) smo poskušali izpostaviti posamezne tipe občin glede na vrsto in število registriranih dopolnilnih dejavnosti na kmetiji. $Z$ vidika številčnega pokazatelja smo vključili v tipizacijo tiste občine, ki so imele v letu 2008 dvajset ali več registriranih dopolnilnih dejavnosti na kmetiji ali je v njih deset in več kmetij, ki so registrirale dopolnilno dejavnost na kmetiji. Pri analizi strukture dopolnilnih dejavnosti v slovenskih občinah pa smo pri poskusu tipizacije upoštevali tiste občine, ki imajo registrirano eno ali več vrst dopolnilnih dejavnosti na kmetiji oziroma je posamezna vrsta dopolnilne dejavnosti zastopana $\mathrm{z}$ vsaj tremi enotami.

Iz razpoložljivih podatkov je bilo mogoče ugotoviti, da je v slovenskih občinah razmerje med posameznimi vrstami dopolnilnih dejavnosti na kmetiji različno: lahko je uravnoteženo (tip C, tudi tip E), ali pa gre lahko za izrazito prevlado ene dejavnosti (tip A). Večkrat gre za kombinacijo nosilne in dopolnilne dejavnosti (tip B), ali pa se zaradi specifičnih lokalnih razmer (fizičnogeografskih, tržnih ipd.) poleg drugih kot relativno pomembna izkaže specifična dejavnost (na primer trsničarstvo, perutninarstvo).

Poskus tipizacije slovenskih občin glede na vrsto dopolnilnih dejavnosti na kmetiji nam izkazuje, da:

- veliko kmetij v Sloveniji že uporablja in še išče različne vire dohodkov;

- je prevlada določene dopolnilne dejavnosti (govorimo lahko že o specializaciji) na nekem območju povezana $\mathrm{z}$ rabo razpoložljivih naravnih in človeških virov ter $\mathrm{s}$ tržnimi zahtevami; 
- je razširjenost dopolnilnih dejavnosti odvisna tako od naravnogeografskih pogojev kot tudi od osebne angažiranosti kmečkih gospodinjstev ter razvoja njihove podjetniške miselnosti;

- so dopolnilne dejavnosti gospodarsko utemeljen vir dohodka, saj prispevajo predvsem $\mathrm{h}$ gospodarski, posledično pa tudi demografski, storitveni, infrastrukturni krepitvi podeželja in njegove identitete;

- so z vidika rabe endogenih razvojnih potencialov kmetije/občine/podeželja dopolnilne dejavnosti (poleg ekoloških kmetij) najnižja raven delovanja (regionalnih) gospodarskih krogov;

- so raznovrstne kombinacije dopolnilnih dejavnosti na kmetiji zelo primerna oblika uravnoteženega razvoja na majhni prostorski enoti.

Slika 6: Poskus tipizacije občin glede na vrsto registriranih dopolnilnih dejavnosti na kmetiji Figure 6: Test typification of Slovene municipalities on the basis of registered supplementary activities on farm

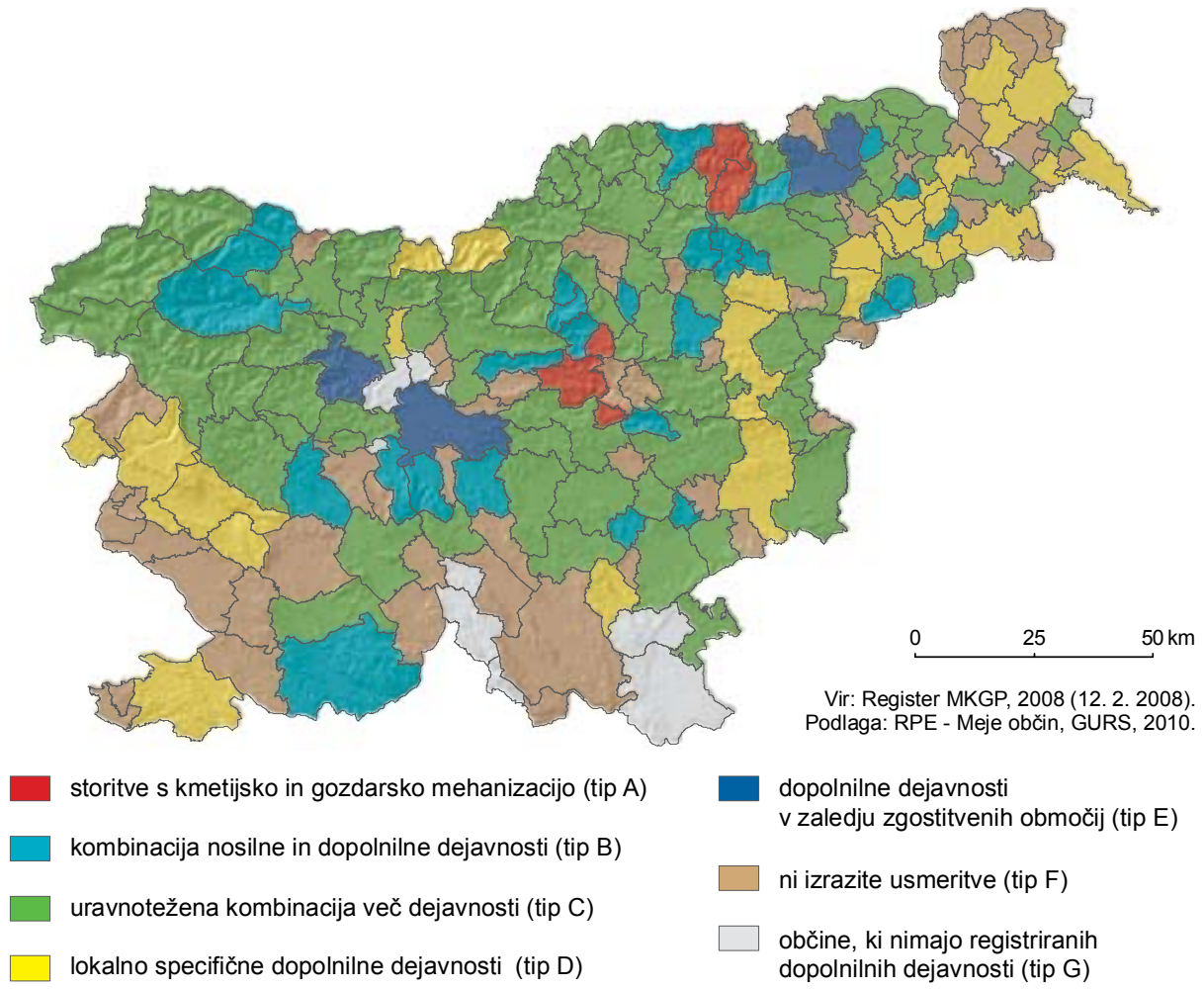

Vir/Source: Ministrstvo za kmetijstvo, gozdarstvo in prehrano (2008) 
Preglednica 1: Kratka oznaka tipov občin glede na registrirane dopolnilne dejavnosti na kmetiji Table 1: Short description of indicated types regarding registered supplementary activities on farms in Slovenian municipalities

Tip A. Kmetije z dopolnilno dejavnostjo na območjih/v občinah, ki imajo razpršeno poselitev $\mathrm{v}$ predalpskem svetu (predvsem $\mathrm{v}$ hribovitem svetu), s precej razširjeno uporabo kmetijske in gozdarske mehanizacije za potrebe pluženja, urejanja cest in predelavo lesa. V občinah Podvelka, Luče, Škofja Loka in Vransko je v absolutnem smislu razvidna prevlada storitev z mehanizacijo, a imajo registrirane tudi druge dopolnilne dejavnosti.

Tip B. Kmetije in občine tipa B imajo razširjene storitve s kmetijsko in gozdarsko mehanizacijo, kateri je dodana še ena dejavnost: običajno turizem na kmetiji ali pridelava in predelava kmetijskih pridelkov (na primer Slovenj Gradec, Tolmin).

Tip C. Kmetije in občine s kombinirano usmeritvijo: storitvam s kmetijsko in gozdarsko mehanizacijo se enakovredno pridružujejo turizem na kmetiji in/ali specializirana dejavnost in/ali predelava in/ali tradicionalna znanja in/ali izobraževanje (Ljutomer, Gorenja vas-Poljane, Idrija, Kranj, Ljubno, Slovenska Bistrica, Velike Lašče).

Tip D. Občine, katerih kmetije z dopolnilno dejavnostjo so se usmerile v specifično dejavnost zaradi kooperantskih odnosov z živilsko-predelovalno industrijo ali grosisti (perutninarstvo in pridelava jajc), zaradi usmerjenosti $\mathrm{v}$ vinogradništvo in sadjarstvo sled ugodnih naravnih pogojev (tudi trsničarstvo, drevesničarstvo, sadike): Vipava, Žalec, Ormož.

Tip E.Občine oziroma kmetije v neposrednem zaledju zgostitvenih območij imajo bolj uravnoteženo kombinacijo več vrst dejavnosti, zaradi bližine trga imajo pomembnejšo vlogo turizem na kmetiji, predelava, vrtnarstvo ipd. (Maribor, Šentjur, Ljubljana, Škofja Loka).

Tip F. V to skupino smo uvrstili občine (58), ki niso zadostile enemu od naslednjih številčnih pogojev: ali so imele manj kot dvajset registriranih dopolnilnih dejavnosti ali so imele manj kot deset kmetij, ki so registrirale dopolnilno dejavnost. Za posebno skupino smo se odločili, ker ima šifrant MKGP 11 kategorij dejavnosti in pri majhnem številu osebkov je običajno prišlo do velike razpršitve registriranih dejavnosti in ni bilo mogoče določiti uvrstitev v kategorije od A do E (zlasti ozemeljsko majhne občine in občine, ki so nastale v letu 2007).

Tip G. Občine, ki nimajo registriranih dopolnilnih dejavnosti na kmetiji (11 občin).

Vir/Source: Ministrstvo za kmetijstvo, gozdarstvo in prehrano (2008)

Obenem smo izvedli polstrukturirani vprašalnik za nosilce dopolnilne dejavnosti na kmetiji (vključenih 252 kmetij, izbranih z metodo naključnega vzorčenja na podlagi podatkov Registra dopolnilnih dejavnosti MKGP). Vprašalnik je vseboval naslednje tematske sklope:

- osnovne značilnosti kmetije $z$ dopolnilno dejavnostjo (človeški in socialni kapital): vrsta dejavnosti (po šifrantu MKGP), leto registracije (in problemi), nosilec in delovna sila (položaj, status, starost, usposobljenost/izobrazba, število opravljenih delovnih ur v povezavi z dopolnilno dejavnostjo), članstvo v društvih, vključevanje v izobraževanje, preobremenjenost;

- $\quad$ vzroki za ukvarjanje z dopolnilno dejavnostjo;

- ključne gospodarsko-tržne informacije (gospodarski kapital): obseg osnovne kmetijske pridelave, predelave in prodaje na kmetiji, prodajni kanali, registrirana blagovna znamka, vključenost v blagovno znamko, samostojen ali skupinski nastop na trgu, uporaba medijev za trženje; 
- ekonomski obseg dopolnilne dejavnosti: obseg dopolnilne dejavnosti, marketinški kanali, nastop na trgu, uporaba medijev za trženje;

- denarna sredstva in razvojna vizija dopolnilne dejavnosti: finančni viri investicij, izdelava poslovnega načrta/promocije ipd., glavni problemi, perspektiva dopolnilnih dejavnosti na kmetiji;

- mnenjska vprašanja: glede uredbe o vrsti, obsegu in pogojih za opravljanje dopolnilnih dejavnosti na kmetiji (največji obseg dohodka, količina proizvodov), glede konkurence, kupcev njihovih proizvodov, razmer na področju dopolnilnih dejavnosti po vključitvi v EU.

Kombinacija uradnih statistik in statistična obdelava anket sta nam pomagali osvetliti zapleteno in medsebojno povezano problematiko, ki so jo nakazovala že naša začetna vprašanja in hipoteza.

\section{UGOTOVITVE}

Pri preučevanju te problematike smo postavili tri hipoteze:

1) da bodo zaradi prepočasnih in skromnih izboljšav agrarne strukture ter zmanjševanja števila družinskih kmetij le-te težko izpolnile strateške funkcije, predvidene v okviru eko-socialnega modela kmetijstva, zato za njih dopolnilne dejavnosti predstavljajo predvsem eksistenčno funkcijo;

2) da predvsem infrastrukturno opremljeno in demografsko dinamično slovensko podeželje predstavlja prostor, kjer se oblikujejo nove poslovne priložnosti (dopolnilne dejavnosti na kmetiji in druge tržno zanimive podjetniške dejavnosti in storitve), ki pa jih (ne)kmečko prebivalstvo še ne uspeva izkoriščati v zadostnem obsegu (ali zaradi nezadostne in neustrezne usposobljenosti, motiviranosti in informiranosti ali pa hitrejšega razvoja ne omogočajo tudi nekateri zunanji dejavniki, na katere posamezna kmetija nima velikega vpliva);

3) da je potencial dopolnilnih dejavnosti na kmetiji pri lokalni oskrbi s hrano in storitvah za potrebe lokalne skupnosti zelo velik.

V raziskavo smo vključili 252 slovenskih kmetij z registrirano dopolnilno dejavnostjo. Osredotočili smo se na tiste dopolnilne dejavnosti, ki so bile $\mathrm{v}$ absolutnem in relativnem smislu hitro rastoče ter tiste, ki zahtevajo večja vlaganja finančnega ali človeškega kapitala (predelava, turizem na kmetiji, storitve $\mathrm{z}$ mehanizacijo in drugo). Med anketiranimi kmetijami jih je 197 imelo registrirano eno, 65 pa dve ali več dejavnosti (slika 7). Med vsemi registriranimi dejavnostmi sta prevladovali predelava (99 kmetij; slika 8) in turizem na kmetiji (85), sledile pa so storitve z mehanizacijo (69), 'prehodne' dejavnosti (32) in umetna kategorija 'ostalo' (združene vse preostale kategorije; 45 kmetij). 68 \% dopolnilnih dejavnosti na kmetiji je bilo registriranih po letu 2000 , izjemno intenzivnost je zaslediti tudi v zadnjih letih (2006-2009; slika 9). 
Slika 7: Anketirane kmetije z registrirano dopolnilno dejavnostjo

Figure 7: Surveyed farms with registered supplementary activity on farm

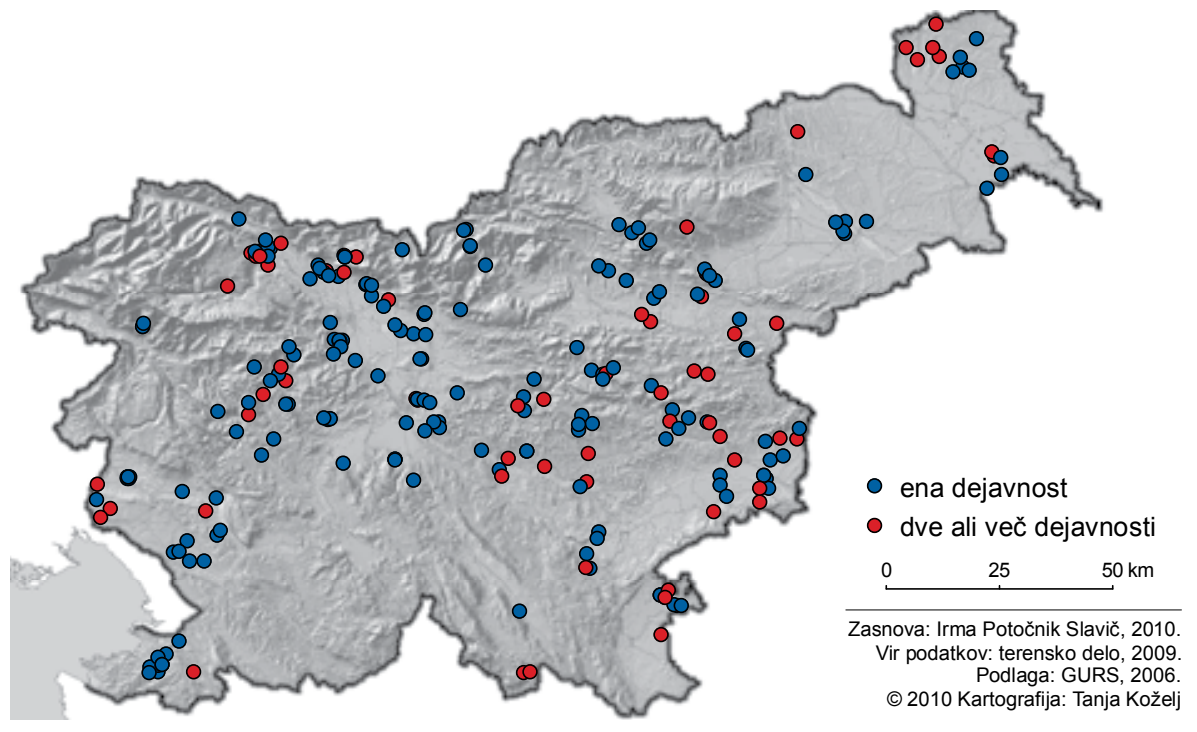

Slika 8: Vrste registriranih dopolnilnih dejavnosti na kmetiji (upoštevana je glavna dopolnilna dejavnost, kot jo je izpostavil njen nosilec)

Figure 8: Varieties of registered supplementary activities on farms (indicated is the main activity declared by the farm holder)

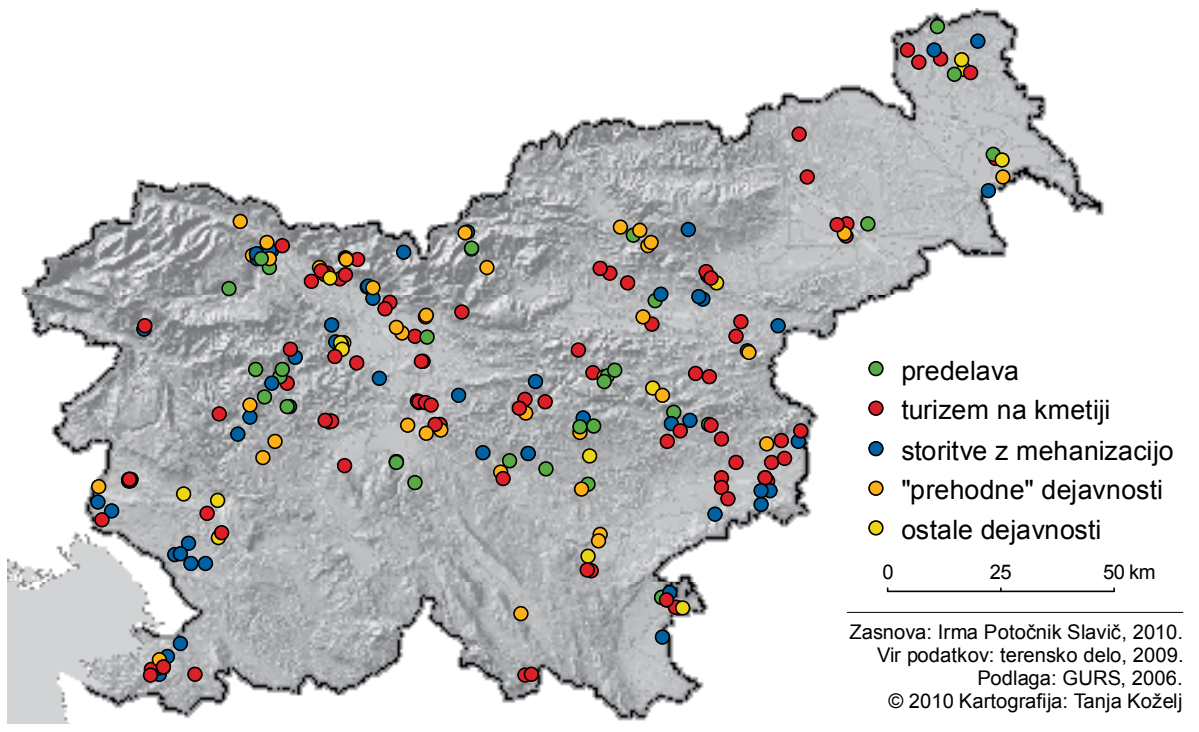


Slika 9: Leto registracije dopolnilne dejavnosti na anketiranih kmetijah

Figure 9: The registration year of surveyed supplementary activities on farm

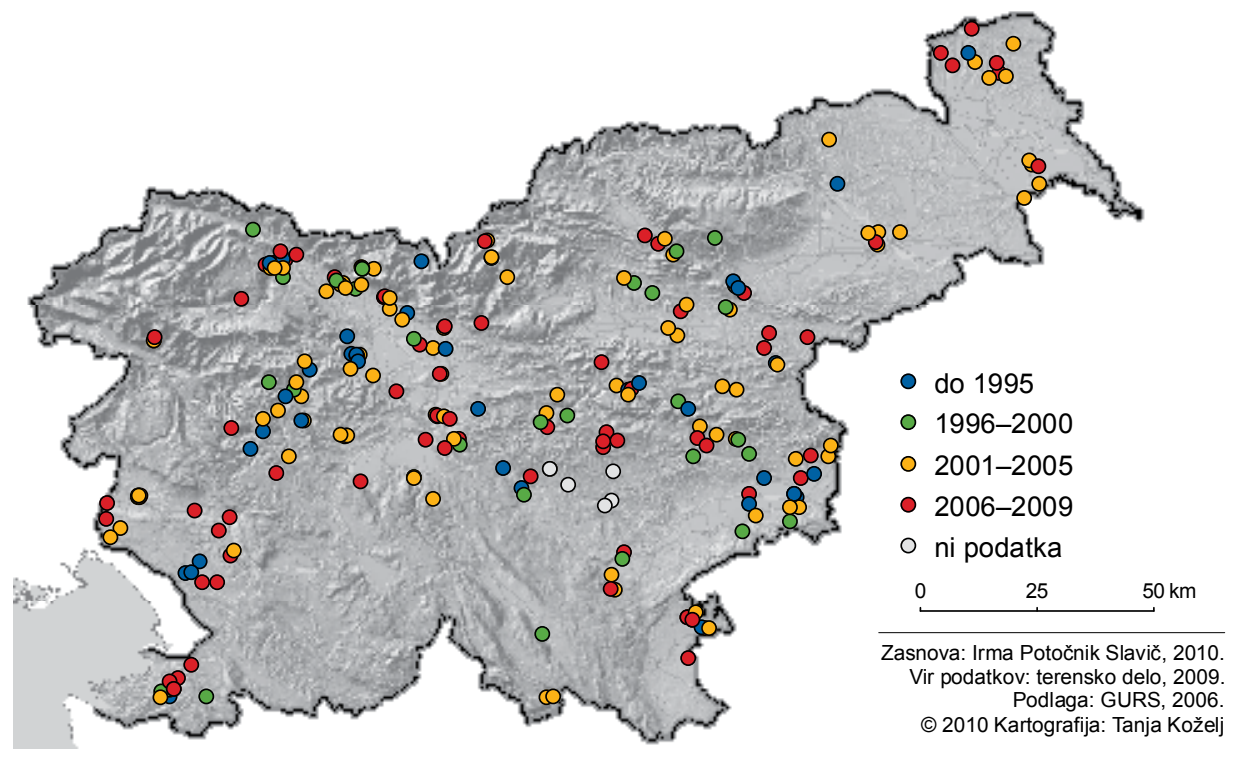

Med anketiranimi nosilci registriranih dopolnilnih dejavnosti na kmetiji je bilo mogoče prepoznati tako starejše kot mlajše kmete. Starejši predstavniki so bili večinoma tisti, ki so se v preteklosti že preizkusili kot kooperanti; pogosto obstoječa dopolnilna dejavnost predstavlja nadaljevanje 'hišne' tradicije (gostinstvo, nekatera specifična znanja). S podobno dediščino so se lahko pohvalili tudi mlajši nosilci, pri katerih pa so nekateri s tovrstno dejavnostjo začeli pionirsko, ker imajo ustrezna znanja, želijo izkoristili potenciale, so inovativni ali pa nagnjeni $\mathrm{k}$ špekulaciji. Najbolj intenzivno in perspektivno se $\mathrm{z}$ dopolnilnimi dejavnostmi ukvarjajo tiste kmetije, kjer je vključeno večje število članov gospodinjstva, ki želijo svojo dejavnost, v katero so vložili veliko različnih oblik kapitala, širiti tudi v prihodnje. Za številne kmetije, ki imajo le sezonsko registrirano dejavnost storitev $\mathrm{z}$ mehanizacijo kot edino dopolnilno dejavnost, le-ta večinoma predstavlja dodaten eksistenčni vir kmečkega gospodinjstva. Med vzroki za registracijo dopolnilnih dejavnosti prevladujejo ekonomski (70 \% ali 319 od 452 vseh odgovorov), sledijo jim razpoložljivi kmetijski proizvodi in tradicija (oba vzroka sta zastopana s po $8 \%$ ). Kot pomanjkljivost v izvedeni raziskavi so se izkazali podatki o količini pridelave in prodaje kmetijskih pridelkov in izdelkov oziroma storitev.

Mogoče je bilo razbrati splošne smernice glede prodajne mreže: anketirane kmetije največ izdelkov/storitev prodajo/nudijo doma ali porabijo/nudijo na domu, na turistični kmetiji ali pa prodajo zadrugi. Rezultati so nakazali še kombinacije drugih tržnih poti (prodaja grosistom, menzam, šolam, na tržnicah, ekoloških in mobilnih tržnicah ipd.). Izpostaviti je potrebno dejstvo, da anketirane kmetije na trgu nastopajo večinoma kot posamezniki brez regi- 
strirane blagovne znamke. Večina anketiranih kmetij oziroma gospodinjstev s kmečkim gospodarstvom je vključenih v več različnih društev: razvidna je velika zastopanost specialističnih društev (vinarjev, oljkarjev, predelovalcev mesa, sirarjev, kmečkih žena itd.), kar je zlasti pomembno za krepitev socialnega kapitala v podeželskih skupnostih.

Obstoječe stanje na anketiranih kmetijah z dopolnilno dejavnostjo namerava ohraniti tretjina kmetij (velika večina je dejavnost pred kratkim registrirala), 40 \% jih namerava povečati dejavnost in razširiti ponudbo (slika 10), le slaba petina pa zaradi različnih razlogov (neurejene razmere na trgu, kriza, pesimizem, problemi z nasledstvom ipd.) v dopolnilni dejavnosti ne vidi zagotovljene prihodnosti.

\section{Slika 10: Perspektiva dopolnilne dejavnosti na anketiranih kmetijah}

Figure 10: The perspective of surveyed farms with registered supplementary activity

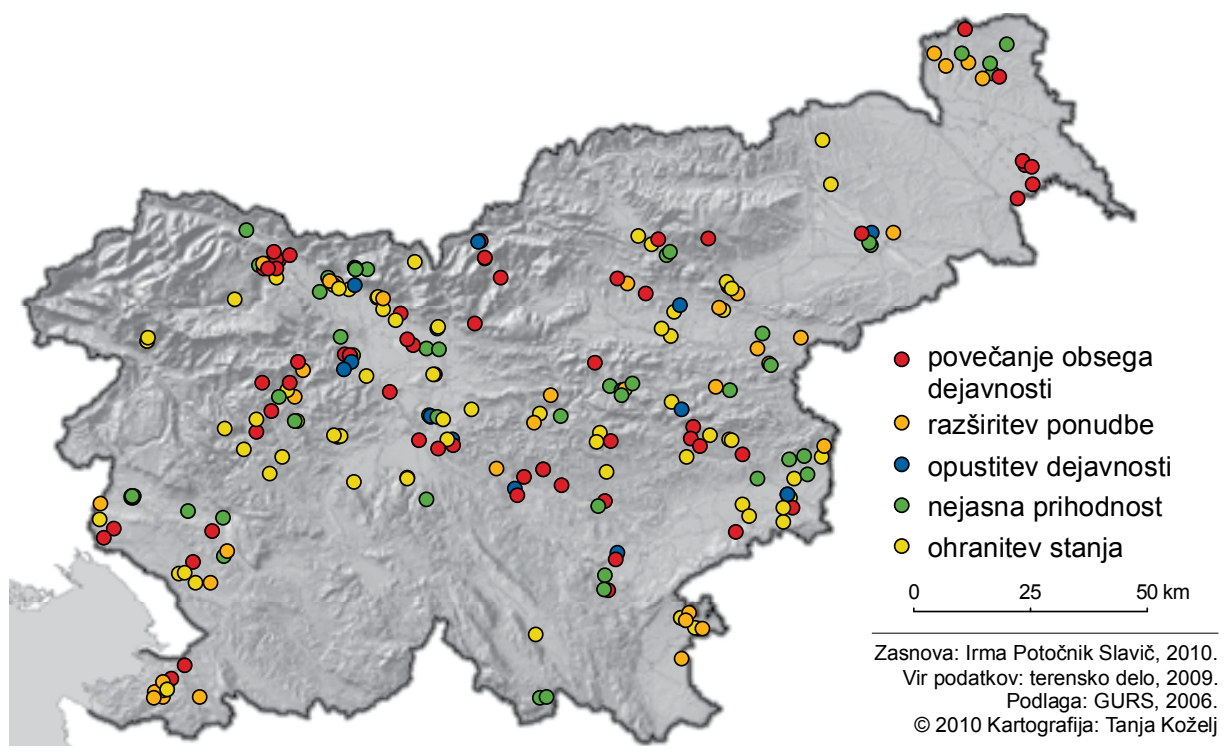

Na preučevanih kmetijah smo kot ključne dejavnike odločanja za dopolnilno dejavnost (ob določeni stopnji posploševanja) prepoznali izjemno vlogo tradicije kmetovanja in delovnih odnosov, fazo družinskega kroga in izobrazbo. Ob analizi dostopnih statističnih podatkov na državni ravni in s terenskim delom, ki je vključilo 252 kmetij z registrirano dopolnilno dejavnostjo na kmetiji, smo izdelali shemo potencialnih učinkov dopolnilnih dejavnosti na kmetiji. Ker predstavljajo kmetije z registrirano dejavnostjo le majhen del slovenskih kmetij (skupaj okrog 75.000), ki je različno intenzivno tržno naravnan, je smiselno razčleniti, kako je kmetija z registrirano dopolnilno dejavnostjo potencialno vključena $\mathrm{v}$ širši sistem (slika 11). $\mathrm{Na}$ ta način nam je bolj jasna njihova vloga pri lokalni oskrbi s hrano ali storitvami. Za podrobnejše ugotovitve bo v prihodnje potrebno analizo na tem področju še poglobiti. 
Slika 11: Notranje in zunanje okolje kmečkega gospodinjstva, ki se odloči za registracijo dopolnilne dejavnosti na kmetiji

Figure 10: Intrinsic and external environment of farm household which has decided to register supplementary activity on farm

ZUNANJE OKOLJE KMEČKEGA GOSPODINJSTVA (A, B, C, D)

\section{A POLTTČñ OKOLE}

(naddržavna, državna, regionalna, lokalna raven)

AGENCIJE

posredujejo priporočila, informacije o financah, ustrezne veščine, znanja (občine, RRA, JAPTI, strukturni skladi itd.)

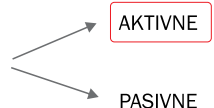

PASIVNE

spodbujanje neoendogenega razvoja

B

ZUNANJI KMETIJSKI VPLIVI

(SKP, cenovne podpore, ESKRP, KSS, kvote,

makroekonomski procesi ipd.)
NOTRANJE OKOUE KMEČKEGA GOSPODINJSTVA

GOSPODARSKI SUBJEKT

(ESU, tržnost, specializacija itd.)

gospodarski potencial

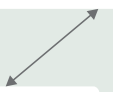

RAZVOJNE

USMERITVE

(na primer:

povečati obseg kmetovanja,

več dejavnosti na kmetiji,

zaposlitev $v$ neagrarnih

dejavnostih, kombiniranje

neagrarnega in agrarnega

dohodka)

Na primer: DOPOLNILNE DEJAVNOST

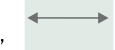
nasledstvo)

\section{C INFORMACIJSKO OKOLI}

(srečanja kmetov, nekmetijske izkušnje članov kmečkega gospodinjstva, sredstva množičnega obveščanja, primeri dobrih praks)

4 socialni potencial

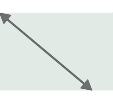

KMEČKO GOSPODINJSTVO

(spol, življenjski krog, starost, poklic, izobrazba,

\section{raba potencialov kmetije}

človeški potencia
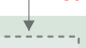

\section{VPLIV NA LOKALNO GOSPODARSTVO}

(odpiranje novih delovnih mest, boljša in raznovrstnejša

ponudba storitev, razvoj infrastrukture, pritiski na okolje, odnos

$z$ dobavitelji in kupci, posebnosti trga, povezanost proizvajalcev,

blagovne znamke)

vključitev v lokalni/regionalni gospodarski krog

Vir/Source: Potočnik Slavič (2008) 


\section{SKLEP}

Glede na pravo renesanso raziskav o lokalni oskrbi je smiselno izpostaviti kritični pogled, opredeljen v treh vidikih (Marsden 2010; Kneafsey 2010; Donald in sod. 2010; Allen 2010 itd.).

1) Regionalna oskrba s hrano oziroma storitvami naj bi omogočila prenos odgovornosti $\mathbf{z}$ osrednje vlade na regionalne ustanove (angl. re-scaling). Prilagoditev razvojnega poudarka lokalnim/regionalnim strukturam je smiselna. Se pa izpostavlja vprašanje, če so te strukture dovolj močne (zmožne) izvesti dodeljene naloge, oziroma če ne generiramo geografijo novih neskladij. Le-to smo praktično dokazali tudi na primeru dopolnilnih dejavnosti na kmetiji, saj nekatera območja izrazito prednjačijo v njihovem razvoju.

2) Regionalna/lokalna oskrba $\mathrm{s}$ hrano in storitvami naj bi prispevala $\mathrm{k}$ poudarjanju regionalnih posebnosti glede proizvodov, prehranjevanja (angl. re-spacing), kar zlasti spodbujajo nove zahteve na trgu. Le-to se je v Sloveniji okrepilo, še vedno pa ne prispeva odločilno k vzpostavitvi regionalnih oskrbnih sistemov. Tako se je na primeru anketiranih kmetij z registrirano dopolnilno dejavnostjo pokazalo, da so se ponekod oskrbne poti in želje po nastopanju na zunanjih trgih še povečale.

3) Regionalna oskrba s hrano in storitvami naj bi prispevala tudi k sodelovanju ljudi pri skupni akciji, povezovanju potrošnika in ponudnika/proizvajalca, pa tudi k odgovornosti za rabo virov, soočenju različnih interesov glede obstoječe in bodoče rabe tal, lastništvu zemlje, vode, prsti itd. (angl. re-connection). Na tem področju se mogoče z vzpostavitvijo regionalnih prehranskih sistemov rojevajo novi akterji; med obstoječimi in novimi lahko prihaja do navzkrižnih gledanj, mogoče je to celo jedro nasprotovanj v prihodnje. Tako tudi na področju dopolnilnih dejavnosti prihaja celo do neskladij znotraj kmetij: ali nadaljevati z osnovno kmetijsko dejavnostjo ali je bolj smotrno razvijati dopolnilno dejavnost ali pa se registrirati kot samostojni podjetnik.

Kljub številnim pozitivnim učinkom, ki jih imajo dopolnilne dejavnosti na kmetiji na lokalno oskrbo s hrano in storitvami, na lokalno gospodarstvo in oskrbo itd., prinaša obravnavana tematika številne vsebinske, metodološke in terminološke nedorečenosti, zato predstavlja novo žarišče geografskega raziskovanja.

\section{Viri in literatura}

Allen, P. 2010: Realizing justice in local food systems. Cambridge journal of regions, economy and society 3, 2. Cambridge.

Donald, B., Gertler, M., Gray, M., Lobao, M. 2010: Re-regionalizing the food system? Cambridge journal of regions, economy and society 3, 2. Cambridge.

Hinrichs, C. C. 2000: Embeddedness and local food systems: notes on two types of direct agricultural market. Journal of rural studies 16, 3. Orlando.

Hofer, K., Stalder, U. 2000: Regionale Produktorganisationen als Transformatoren des Bedürfnisfeldes Ernährung in Richtung Nachhaltigheit? Potentiale-Effekte-Strategien. Geographica Bernensia, Reihe P 37, Geographisches Institut der Universität Bern. Bern. 
Klemenčič, M. M., Lampič, B., Potočnik Slavič, I. 2008: Življenjska (ne)moč obrobnih podeželskih območij v Sloveniji (GeograFF, 3). Znanstvena založba Filozofske fakultete, Oddelek za geografijo. Ljubljana.

Kneafsey, M. 2010: The region in food - important or irrelevant? Cambridge journal of regions, economy and society 3,2 . Cambridge.

Kovačič, M. 2001: Podjetniške in sociološke značilnosti kmetij v Sloveniji. V: Učinki reforme slovenske kmetijske politike. 1. konferenca Društva agrarnih ekonomistov Slovenije (Ljubljana, 1. oktober 2001). Ljubljana.

Maier, J. 2002: Regional economic cycles as an instrument of a sustainable regional development in rural areas. Dela 17, Oddelek za geografijo Filozofske fakultete Univerze v Ljubljani. Ljubljana.

Marsden, T. 2010: Mobilizing the regional eco-economy: evolving webs of agri-food and rural development in the UK. Cambridge journal of regions, economy and society 3, 2. Cambridge

Potočnik Slavič, I. 2008: Endogeni razvojni potenciali podeželja. Doktorska disertacija, Oddelek za geografijo, Filozofska fakulteta Univerze v Ljubljani. Ljubljana.

Potočnik Slavič, I. 2010: Endogeni razvojni potenciali slovenskega podeželja (GeograFF, 7). Znanstvena založba Filozofske fakultete. Ljubljana.

Register dopolnilnih dejavnosti na kmetiji, 2008. Ministrstvo za kmetijstvo, gozdarstvo in prehrano.

Uredba o vrsti, obsegu in pogojih za opravljanje dopolnilnih dejavnosti na kmetiji. Uradni list RS 61/2005. Ljubljana.

Pravilnik o registraciji dopolnilnih dejavnosti na kmetiji. Uradni list RS 79/2005. Ljubljana. Pravilnik o usposobljenosti za opravljanje dopolnilnih dejavnosti na kmetiji. Uradni list RS $31 / 2005$ in 105/2006. Ljubljana.

\section{FARMERS' INTEGRATION INTO PROVISION NETWORKS: THE CASE OF SUPPLEMENTARY ACTIVITIES ON FARMS IN SLOVENIA}

\section{Summary}

According to the available data resulting from the Agricultural Census (2000) and the relevant number of applicants for CAP subsidies, there are approx. 75,000 farms in Slovenia. The majority of them are self-sufficient. Due to the fact that there are just few professional farms and that the agriculture has become less important economic activity (»additional activity«) in Slovenian rural areas, we have observed an evident increase of on-farm income diversification in the last decade. The later was perceived by the official Register of supplementary activities on farms, under the supervision of the Ministry of Agriculture, Forestry and Food.

The focus of this paper is to recognize the importance of farms that are trying to establish their market niche, especially via local food and services provision. In 2008, there were 4716 
registered supplementary activities and 2802 farms were involved (each farm is allowed to register one or more activities). Currently, there are 11 groups of activities permitted by the regulation: food-processing, tourism on farms, services with farm mechanization, provision of renewable energy, services associated with farm tradition etc. Comparing the data from 2004 and 2008, we have registered an increase of index 213, pointing out that this relatively »users friendly« tax and market opportunity is quite favourable for some farms in Slovenia.

The theoretical background of on-farm diversification usually recognizes three types of activities: agricultural activities being part of agricultural industry (for example co-operants specialized in poultry farming), small-scale agricultural activities connected to various knowledge of household members (on-farm food processing) and non-agricultural activities (tourism on farm, educational activities etc.). We present some results of extensive field survey (carried out in late 2009 and early 2010) on a sample of 252 farms with registered supplementary activity on farm. We deliberately included activities that require more capital and human resources investment: mostly tourism on farm and food-processing. The semistructured questionnaire was focused on basic characteristics of farm household, reasons essential for each farm to register one or more activities on farm, information on economics and production issues of farm, marketing and trade channels, used and potential financial resources, and also the question on future vision of the included farms.

Our research was based on three hypothesis:

1) that due to slow and modest improvements of agricultural structure and decrease of total numbers of family farms in Slovenia, they will potentially not be capable to fulfil strategic objectives of eco-social agricultural model; therefore supplementary activities act as one's livelihood opportunity;

2) that especially infrastructurally equipped and demographically dynamic Slovene rural areas represent a territory where new entrepreneurial opportunities occur (supplementary activities on farms, other market-interesting entrepreneurial activities and services), which have not been used enough by (non)agricultural rural population due to various reasons (insufficient knowledge and skills, lack of motivation and information gathering, also the importance of external factors etc.);

3) that the potential of supplementary activities on farms is extremely important in local food and services provision.

In the sample, 197 farms registered one, 65 registered two or more activities: our survey included farms with food-processing (99 farms), tourism on farms ( 85 farms), services with agricultural mechanization (69 farms) etc. $68 \%$ of observed activities were registered after 2000, with evident vivid intensity in period 2006-2009.

The holders of supplementary activities are older and younger farmers:

- the older with previous experience of co-operants relations, usually following the »house tradition« (tavern, specific skills),

- similar structure is also evident with younger holders; but some have taken a pioneer route implementing relevant knowledge and potentials, are innovative. 
Focusing on reasons that motivated farmers to register on-farm diversification, our survey noticed the importance of economic reasons ( $70 \%$ of all responses), followed by the available agricultural products ( $8 \%$ of responses), also the family tradition ( $8 \%$ ). We noticed that we were not able to collect relevant data on the production quantities and turnover of agricultural products and services. We were able to trace general market routes: most surveyed farms offer their products/services at home, on tourism on farm or they offer their assortment to the co-operative. We also noticed various combinations of other market channels (wholesale, factory's kitchen, schools, traditional, organic and mobile open-air markets etc.). Farmers are represented usually on the market individually with no registered trade mark, although the farm household members are participating in various associations and clubs in rural areas, being very important for the strengthening of social capital (professional societies of wine, olive oil, cheese producers, meat-processors, farm women etc.).

Surveyed farms indicated that they will keep the existing activity as status quo (one third of surveyed farms), $40 \%$ of farms intend to extend and enlarge their offer, less than $20 \%$ of farms do not evaluate supplementary activity as a development opportunity for their farm (mostly because on unclear market circumstances, crisis, pessimism, problems with successors). Surveyed farms indicated the importance of the family or farm tradition, the farm family life-cycle and education. As farms with registered activity on farms represent only a modest share of Slovenian farms, interested in market production, we also analysed how the surveyed farms are included in broader system, for example in local food and services provision. For more detailed results one should make some more in-depth analysis in the future. 